\title{
Modern Swarm Intelligence based Algorithms for Solving Optimal Power Flow Problem in a Regulated Power System Framework
}

\author{
Vijaya Bhaskar K*, Ramesh $\mathbf{S}^{1}$, Abudhahir $\mathbf{A}^{2}$ \\ ${ }^{*}, 1,2$ Department of Electrical and Electronics Engineering, Vel Tech Rangarajan Dr. Sagunthala R\&D Institute of \\ Science and Technology, India. \\ *Corresponding author's e-mail: vijayk252@gmail.com
}

Article History: Received: 10 November 2020; Revised: 12 January 2021; Accepted: 27 January 2021; Published online: 05 April 2021

\begin{abstract}
This paper presents artificial swarm intelligent based algorithms viz., Firefly Algorithm (FFA), Dragonfly Algorithm (DA) and Moth Swarm Algorithm (MSA) to take care of the issues related to optimal power flow (OPF) problem in a power system network. The optimal values of various decision variables obtained by swarm intelligent based algorithms can optimize various objective function of OPF problem. This article is focused with four objectives such as minimization of total fuel cost (TFC) and total active power loss (TAPL); improvisation of total voltage profile (TVD) and voltage stability index (VSI). The effectiveness of various swam intelligent algorithms are investigated on a standard IEEE-30 bus. The performance of distinct algorithms is compared with statistical measures and convergence characteristics.
\end{abstract}

Keywords: Dragonfly algorithm, Firefly algorithm, Moth swarm algorithm, Optimal power flow, Swarm intelligence

\section{Introduction}

The optimal power flow (OPF) problem is a familiar problem in an interconnected power system network. The OPF solution gives optimal values of generators, transformers, reactive compensating devices through which different objectives can be optimized. The objective function of OPF problem has to meet out constraints in the form of hard (equality) and soft (inequality) constraints which make the problem to become more complex, multi-modal and non-convex problem. The traditional methods such as linear programming, gradient based methods and quadratic programming are suffered with local convergence in order to obtain global optimal value [1]. So as to defeat the disadvantages of traditional methods, artificial swarm intelligent based algorithms have been used in this article for solving OPF problem. The swarm intelligent based algorithms viz., Firefly algorithm, Moth swarm algorithm and Dragonfly algorithm can handle multi-modal problem effectively and has fast convergence rate [2].

The Firefly Algorithm (FFA) is one of the swarm intelligent based algorithms developed by Xin-SheYang based on the attracting behaviour of fireflies [3]. All the fireflies are viewed as unisexual and their fascination is straight-forwarded to their glimmering light illumination. The firefly with lower illumination moves towards the firefly with higher light illumination. In the event that there are no fireflies close by or the fireflies have same illumination, the firefly will move an irregular way. The illumination of blaze is related with the fitness value. The light force likewise complies with the reverse square law [4].

The Moth Swarm Algorithm (MSA) is suggested by Al-Attar Ali Mohammad in 2016 is dependent on the direction of moths in an uproarious climate towards light of the moon [5]. Moth swarm comprises of three groups of moths, namely, pathfinders, prospectors and onlookers. Pathfinders' is a little gathering of moths that can find new regions over the improvement space. This is to segregate the optimal positions of the light source to control the development of the principle swarm. Next, prospectors' is a gathering of moths that will roam in an irregular way inside the neighborhood of the light sources and are set apart from pathfinders. Onlookers are a group of moths that can float straightforwardly toward the optimal arrangement that has been acquired by prospectors [6].

The dragonfly algorithm (DA) is another artificial swarm intelligent algorithm and is based on the behaviour of dragonflies described by Mirjalili in 2016 [7]. The population of DA has five behaviours, namely separation (staying away from impacts among the dragonflies), alignment (keeping up the trip among the dragonfly gathering), cohesion (moving close to each other individual), foraging and eluding enemies [8].

\section{Problem Formulation}

The OPF problem can be numerically represented as $\min \mathrm{OF}(X, \mathrm{U})$ exposed to 


$$
\begin{array}{rl}
\mathrm{G}_{\mathrm{j}}(\mathrm{X}, \mathrm{U})=0 & \mathrm{j}=1,2,3, \ldots \ldots \ldots \ldots \ldots \mathrm{m} \\
\mathrm{H}_{\mathrm{j}}(X, \mathrm{U}) \leq 0 & \mathrm{j}=1,2,3, \ldots \ldots \ldots \ldots \mathrm{p}
\end{array}
$$

where OF: target function which has to be minimized, $\mathrm{X}$ : control variables vector, $\mathrm{U}$ :state variables vector, $\mathrm{G}_{\mathrm{j}}$ : hard (equality) constraint, $\mathrm{H}_{\mathrm{j}}$ : soft (inequality) constraint, $\mathrm{m}$ : no. of hard constraints, $\mathrm{p}:$ no. of soft constraints.

The state vector $\mathrm{X}$ in power system can be represented as eq.3

$\mathrm{X}=\left[\mathrm{P}_{\mathrm{G} 1}, \mathrm{~V}_{\mathrm{L} 1}, \ldots \mathrm{V}_{\mathrm{LNPQ}}, \mathrm{Q}_{\mathrm{G} 1}, \ldots \mathrm{Q}_{\mathrm{GNG}}, \mathrm{S}_{\mathrm{TL} 1}, \ldots, \mathrm{S}_{\mathrm{TLNTL}}\right]$

where $\mathrm{P}_{\mathrm{G} 1}$ : $\mathrm{MW}$ of slack bus, $\mathrm{V}_{\mathrm{L}}: \mathrm{MV}$ of load bus, $\mathrm{Q}_{\mathrm{G}}:$ MVAR of generator bus, $\mathrm{S}_{\mathrm{TL}}: \mathrm{MVA}$ flow in transmission line, NPQ : no. of load bus, NG : no. of generator bus, NTL : no. of transmission lines

The control vector $\mathrm{U}$ in power system can be represented as eq.4

$\mathrm{U}=\left[\mathrm{P}_{\mathrm{G} 2}, \ldots \mathrm{P}_{\mathrm{GNG}}, \mathrm{V}_{\mathrm{G} 1}, \ldots, \mathrm{V}_{\mathrm{GNG}}, \mathrm{Q}_{\mathrm{C} 1}, \ldots \mathrm{Q}_{\mathrm{CNC}}, \mathrm{T}_{1}, \ldots \mathrm{T}_{\mathrm{NT}}\right]$

where $\mathrm{P}_{\mathrm{G}}$ : MVA of generator bus, $\mathrm{V}_{\mathrm{G}}: \mathrm{MV}$ of generator bus, $\mathrm{Q}_{\mathrm{C}}$ : MVAR of shunt compensator, $\mathrm{T}$ : transformer tap settings, NC : no. of shunt compensators, NT : no. of transformers.

\subsection{Objective Functions}

1). Case-1: The target element is to limit the total fuel cost which is expressed as eq.5

$$
\text { OF_1 } 1=\sum_{i=1}^{N G} F_{i}\left(P_{G i}\right)=\sum_{i=1}^{N P V}\left(a_{i} P_{G i}^{2}+b_{i} P_{G i}+c_{i}\right)
$$

where $F_{i}$ : fuel cost of generator-i, $a_{i}, b_{i}, c_{i}$ are the cost coefficients of generator- $i$

2). Case-2: The target element is to limit the total active power loss which is expressed as eq.6

$$
\text { OF_2 }=\mathrm{P}_{\text {loss }}=\sum_{\mathrm{i}=1}^{\mathrm{NTL}} \mathrm{G}_{\mathrm{ij}}\left(\mathrm{V}_{\mathrm{i}}^{2}+\mathrm{V}_{\mathrm{j}}^{2}-2 \mathrm{~V}_{\mathrm{i}} \mathrm{V}_{\mathrm{j}} \cos \delta_{\mathrm{ij}}\right)
$$

Where $G_{i j}$ : conductance of transmission line of bus i and bus $j, \delta_{i j}$ : voltage phase difference between bus $i$ and bus j.

3). Case-3: The target element is to limit the total voltage deviation of load bus from specified voltage which is expressed as eq.7

$$
\text { OF_3 }=\mathrm{VD}=\sum_{\mathrm{i}=1}^{\mathrm{NPQ}}\left|\left(\mathrm{V}_{\mathrm{i}}-1\right)\right|
$$

4). Case-4: The target element is to limit the voltage stability index (L) value, thereby keep the system far away from voltage collapse. The objective function is expressed as eq.8

$$
\text { OF_4 }=\min \left(\mathrm{L}_{\max }\right)=\min \left(\max \left(\mathrm{L}_{\mathrm{n}}\right)\right) \mathrm{n}=1 \ldots, \mathrm{NPQ}
$$

\subsection{Equality constraints}

$$
\begin{aligned}
& P_{G i}-P_{D i}-\left|V_{i}\right| \sum_{j=1}^{N B}\left|V_{j}\right|\left(G_{i j} \cos \delta_{i j}+B_{i j} \sin \delta_{i j}\right)=0 \\
& Q_{G i}-Q_{D i}-\left|V_{i}\right| \sum_{j=1}^{N B}\left|V_{j}\right|\left(G_{i j} \sin \delta_{i j}-B_{i j} \cos \delta_{i j}\right)=0
\end{aligned}
$$

\begin{tabular}{|c|c|c|}
\hline Generators MW & $\mathrm{P}_{\mathrm{Gi}}^{\min } \leq \mathrm{P}_{\mathrm{Gi}} \leq \mathrm{P}_{\mathrm{Gi}}^{\max }$ & $i=1,2,3, \ldots$ \\
\hline Generator bus voltages $V_{\mathrm{Gi}}^{\min }$ & $\mathrm{V}_{\mathrm{Gi}} \leq \mathrm{V}_{\mathrm{Gi}}^{\max }$ & $i=1,2,3, \ldots$ \\
\hline Generator MVAR & $\mathrm{Q}_{\mathrm{Gi}}^{\min } \leq \mathrm{Q}_{\mathrm{Gi}} \leq \mathrm{Q}_{\mathrm{Gi}}^{\max }$ & $\mathrm{i}=1,2,3,$. \\
\hline Transformer tap settings & $\mathrm{T}_{\mathrm{i}}^{\min } \leq \mathrm{T}_{\mathrm{i}} \leq \mathrm{T}_{\mathrm{i}}^{\max }$ & $\mathrm{i}=1,2,3,$. \\
\hline MVAR shunt compensator & $\mathrm{Q}_{\mathrm{Ci}}^{\min } \leq \mathrm{Q}_{\mathrm{Ci}} \leq \mathrm{Q}_{\mathrm{Ci}}^{\max }$ & $i=1,2,3$, \\
\hline MVA flow in transmission 1 & es $\mathrm{S}_{\mathrm{Li}} \leq \mathrm{S}_{\mathrm{Li}}^{\min }$ & $\mathrm{i}=1,2,3$ \\
\hline Voltage magnitude of load $b$ & es $V_{\mathrm{Li}}^{\min } \leq \mathrm{V}_{\mathrm{Li}} \leq \mathrm{V}_{\mathrm{Li}}^{\max }$ & $\mathrm{i}=1,2,3$, \\
\hline
\end{tabular}

where $\mathrm{P}_{\mathrm{Gi}}$ :MW at bus $\mathrm{i}, \mathrm{Q}_{\mathrm{Gi}}$ : MVAR at bus i, $\mathrm{P}_{\mathrm{Di}}$ : MW load demand at bus $\mathrm{i}, \mathrm{Q}_{\mathrm{Di}}$ : MVAR load demand at bus $\mathrm{i}, \mathrm{B}_{\mathrm{ij}}$ : susceptance of transmission line from bus $\mathrm{i}$ to bus $\mathrm{j}, \mathrm{V}_{\mathrm{i}}$ : voltage at bus $\mathrm{i}, \mathrm{V}_{\mathrm{j}}$ : voltage at bus $\mathrm{j}$.

\subsection{Inequality constraints}

\section{Methodology}

This section presents pseudo-codes for FFA, DA and MSA algorithms.

The pseudo code for FFA is given below [9]:

Initialization

Initialize the measurements of the issue (25/49), the population size (50), maximum number of iterations (200), choose the values of $\alpha, \beta, \gamma, \delta$ as $0.2,2,1$ and 0.98

Initialize the iteration counter

Check for stopping criteria.

Stop and Display the results

Otherwise 
Evaluate the fitness function.

$$
I=I_{0} \exp \left(-\gamma \cdot r^{2}\right)
$$

where $\mathrm{I}_{0}$ is unique light force, $\gamma$ is assimilation (absorption) co-effective, $r$ is separation between fireflies.

Assess the attractiveness of firefly.

$$
\beta(r)=\beta_{0} \exp \left(-\gamma \cdot r^{2}\right)
$$

Where $\beta(r)$ is monotonically decreasing function and $\beta_{0}$ is attractiveness at $\mathrm{r}=0$

Assess the development of firefly towards brightness

$x_{i}=x_{i}+\beta_{0} \exp \left(-\gamma \cdot r_{i, j}^{2}\left(x_{j}-x_{i}\right)+\alpha(\right.$ rand -0.5$)$

$r_{i, j}=\left\|x_{i}-x_{j}\right\|=\sqrt{\sum_{k=1}^{d}\left(x_{i, k}-x_{j, k}\right)^{2}}$

Where $\alpha$ being the step number varied (random moment), rand is contingent number varied between $[0,1], \mathrm{r}_{\mathrm{i}, \mathrm{j}}$ is Cartesian separation from firefly-i to firefly-j.

Increment the iteration

\section{The pseudo code for MSA is given below [10]:}

Initialization

Instate the population

Calculate the fitness of the population and categorize the type of moth

While iteration < maximum iteration size

Phase-I: Reconnaissance phase

Distinguish the hybrid focuses.

Produce Levy battles tests.

Change the trail vector

Build the finished trial solution.

Choose the artificial light sources

Ascertain the random probability based values.

Phase-II: Transverse orientation

For every moth prospector

Update position.

Evaluate fitness.

$$
\text { End }
$$

Determine the new light sources and moonlight.

Phase-III: Celestial Navigation

For every onlooker moth

Renew the situation accordingly.

Develop Gaussian walks

If $i \in n_{G} \quad$ Migrate the situation to developed Gaussian walks

Else if Float the onlooker moth

End.

$$
\text { End }
$$

Ascertain the wellness of onlooker moth.

Distinguish the new light sources and twilight, and sort of moth.

Obtain the global best solution.

The pseudo code for DA is given below [11]:

Instate the dragon-flies population.

Introduce the progression vectors.

While stop condition is not fulfilled.

Compute the target element wellness values.

Update weights of inertia (w), alignment (a), cohesion (c), food (f), enemy (e), separation (s).

Update neighbouring spam.

In the event that if a dragon flies has atleast one neighbouring dragon fly

Update the speed vector.

Update the position vector.

Else

Update the position vector.

End if.

Test and assign the new positions dependent on the limits of factors.

End while. 


\section{Results and Discussions}

The swarm intelligent algorithms discussed in Section III are applied for standard test system(IEEE-30 bus system) and practical test system (62-bus Indian system) and the simulation is carried out in a PC with 64-bit Windows 7 OS having i5 Intel processor operating at $3.2 \mathrm{GHz}$ with RAM of 6GB. The results are obtained by using MATPOWER 7.0 in MATLAB 2013b. A maximum number of iterations are set as 200. A number of search agents are taken as 50 and 25 individual runs have been conducted to obtain best optimal value for each objective function.

\subsection{Standard Test System: (IEEE-30 Bus System)}

The parameters that show effect on FFA are mutation co-efficient $(\alpha)$, initial attractive co-efficient $(\beta)$, absorption co-efficient $(\gamma)$, mutation co-efficient damping ratio $(\delta)$. The best value of the parameters at which the test system gives optimal value are considered as $\alpha=0.2, \beta=2, \gamma=1, \delta=0.98$. The specification that has significance on MSA is the number of pathfinders which should be greater than 4 and lesser than $20 \%$ of the search agents. Therefore, the number of pathfinders is 8. DA is controlled by parameters like weights of inertia (w), enemy distraction (e), separation (s), alignment (a), cohension (c) \& food attraction (f). Inertia weight is varied from 0.4 to 0.9 . The inertia weight is considered as $\mathrm{w}=0.9$. Enemy distraction weight is varied in between 0 and 0.9 and the best value is taken as e $=0.1$. The remaining specifications $\mathrm{s}, \mathrm{a}, \mathrm{c}, \mathrm{f}$ are random values between 0 and 1 . The parameter settings of swarm intelligence algorithm are given below Table 1.

Table 1. Parameter Settings.

\begin{tabular}{llll}
\hline FFA & Values & DA & Values \\
\hline Mutation Co-efficient $(\alpha)$ & 0.2 & Inertia weight $(w)$ & 0.9 \\
Initial Attractive Co-efficient $\left(\beta_{0}\right)$ & 2 & Enemy distraction weight $(\mathrm{e})$ & 0.1 \\
Absorption Co-efficient $(\gamma)$ & 1 & Seperation $(\mathrm{s})$, alignment $(\mathrm{a})$, & Random \\
Mutation damping ratio $(\delta)$ & 0.98 & cohension $(\mathrm{c})$, food attraction $(\mathrm{f})$ & {$[0,1]$} \\
\hline For MSA, the parameter that influence is the number of pathfinders which is equal to 8 &
\end{tabular}

The best parameter values for the FFA are given in the Table 2. The best value is noticed at which the objective function has given best fit value. The minimization of total fuel cost for standard test system is considered as the objective function. The best fit value for the objective function is 802.1310 given at $\alpha=0.2$, $\beta=2, \gamma=1, \delta=0.98$. $\alpha$ is varied from 0.1 to 0.8 and the optimal value is 0.2 . $\beta$ is varied from 0.5 to 4 and the optimal value is 2 . The optimal value is obtained at $\gamma=1$ by varying from 0.4 to 1.4 . $\delta$ is varied with the interval of 0.02 from 0.92 to 1.04 and the best value is given at 0.98 . The best parameter values are obtained by conducting 100 iterations with 20 search agents and 10 individual trials.

Table 2. Best Parameter Settings for FFA.

\begin{tabular}{lllll}
\hline $\begin{array}{l}\text { Mutation } \\
\text { Co-efficient }(\alpha)\end{array}$ & Initial Attractive & Co-efficient $(\beta)$ & Absorption & Mutation \\
Co-efficient $(\gamma)$ & damping Ratio $(\delta)$ & $\begin{array}{l}\text { Best Fit } \\
\text { Value }\end{array}$ \\
\hline 0.2 & 2 & 1 & 0.98 & 802.1310 \\
0.3 & 2 & 1 & 0.98 & 802.1313 \\
0.4 & 2 & 1 & 0.98 & 802.1324 \\
0.6 & 2 & 1 & 0.98 & 802.1326 \\
0.8 & 2 & 1 & 0.98 & 802.1323 \\
0.1 & 2 & 1 & 0.98 & 802.1312 \\
0.2 & 1 & 1 & 0.98 & 802.2202 \\
0.2 & 1.5 & 1 & 0.98 & 802.1384 \\
0.2 & 2.5 & 1 & 0.98 & 802.1312 \\
0.2 & 3 & 1 & 0.98 & 802.1312 \\
0.2 & 4 & 1 & 0.98 & 802.1314 \\
0.2 & 0.5 & 1 & 0.98 & 802.2232 \\
0.2 & 2 & 0.5 & 0.98 & 802.1314 \\
0.2 & 2 & 0.8 & 0.98 & 802.1335 \\
0.2 & 2 & 1.2 & 0.98 & 802.1359 \\
0.2 & 2 & 1.4 & 0.98 & 802.1363 \\
0.2 & 2 & 0.6 & 0.98 & 802.1368 \\
0.2 & 2 & 0.4 & 0.98 & 802.1315 \\
0.2 & 2 & 1 & 1 & 802.1335 \\
0.2 & 2 & 1 & 1.02 & 802.1346
\end{tabular}




\begin{tabular}{lllll}
0.2 & 2 & 1 & 1.04 & 802.1352 \\
0.2 & 2 & 1 & 0.96 & 802.1333 \\
0.2 & 2 & 1 & 0.94 & 802.1359 \\
0.2 & 2 & 1 & 0.92 & 802.1419 \\
\hline
\end{tabular}

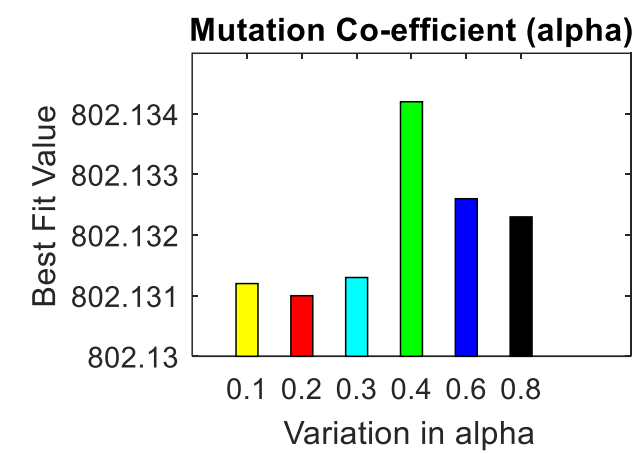

Figure 1. Variation in $\alpha$.

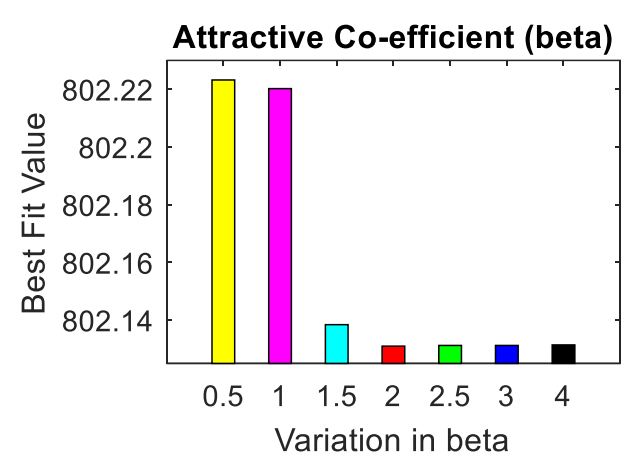

Figure 2. Variation in $\beta$.

The best fit value of objective function with variation of $\alpha$ is shown in Figure 1. The best fit value of objective function with variation of $\beta$ is shown in Figure 2. The best fit value of objective function with variation of $\gamma$ is shown in Figure 3. The best fit value of objective function with variation of $\delta$ is shown in Figure 4.

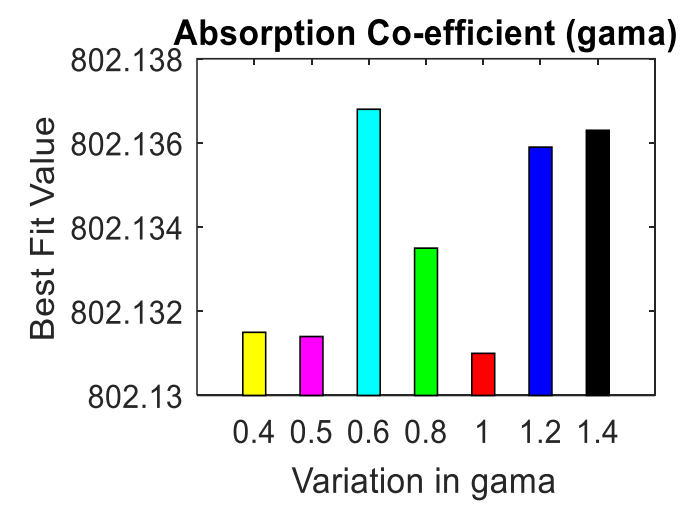

Figure 3. Variation in $\gamma$.

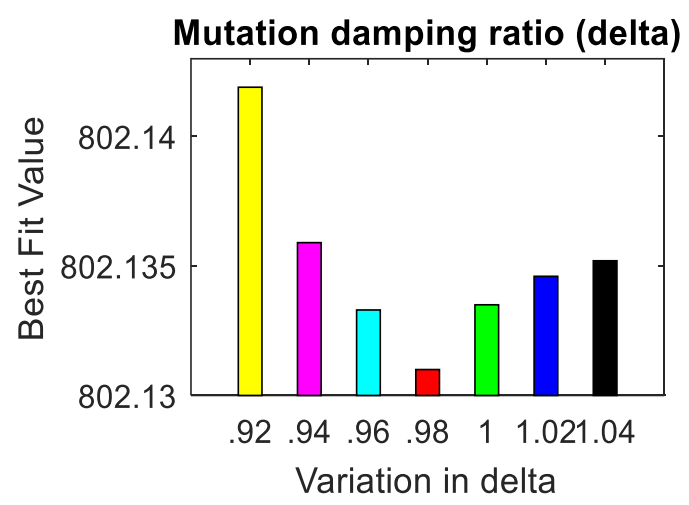

Figure 4. Variation in $\delta$.

Table 3 shows the best fit value of the objective function with different values of $\delta, \beta, \gamma, \delta$. The best fit value for the objective function is 802.1310 is obtained with the values of $\alpha=0.2, \beta=2, \gamma=1, \delta=0.98$. The best fit value of objective function with different values of $\delta, \beta, \gamma, \delta$ as P1, P2, P3, P4, P5, P6, P7 is shown in Figure 5.

The optimal values of control variables for each objective function of standard test system using FFA is given in Table 4. The range of voltage magnitude is 0.95 and 1.1. The minimum and maximum transformer tap setting ratio is 0.9 and 1.1. The variation of shunt compensator is from 0-5 MVAR. About 25 variables are taken as decision variables. The decision variables are generated MVA at bus no 1,2,5,8,11,13, generated MV at bus no $1,2,5,8,11,13$, transformer tap setting ratio at branch no 11,12,15,36 and MVAR shunt compensators at bus no $10,12,15,17,20,21,23,24,29$. A comparison of the best value for each objective function using DA and MSA with FFA is given in Table 5. By comparison, the FFA gives the minimum optimized value for all objective functions. The convergence characteristic curves of four cases for Standard test system are shown in Figure 6Figure 9. The best, mean, worst values of each objective function with FFA, MSA, DA for Standard test system are given in Table 6. The best optimal value given by FFA is very close to mean value for all objective functions for standard test system. FFA is more efficient than MSA and DA for standard test system in the view of success rate, global optimal value as well as iterations.

Table 3. Different Values of $\delta, \beta, \gamma, \delta$.

\begin{tabular}{llllll}
\hline \multirow{2}{*}{ Parameter Settings } & $\begin{array}{l}\text { Mutation } \\
\text { Co-efficient }(\alpha)\end{array}$ & $\begin{array}{l}\text { Initial Attractive } \\
\text { Co-efficient }(\beta)\end{array}$ & $\begin{array}{l}\text { Absorption } \\
\text { Co-efficient }(\gamma)\end{array}$ & $\begin{array}{l}\text { Mutation } \\
\text { damping Ratio }(\delta)\end{array}$ & $\begin{array}{l}\text { Best Fit } \\
\text { Value }\end{array}$ \\
\hline P1 & 0.2 & 2 & 1 & 0.98 & 802.1310 \\
P2 & 0.1 & 1.5 & 0.8 & 0.92 & 802.1897
\end{tabular}




\begin{tabular}{llllll}
\hline & & & & & \\
P3 & 0.3 & 0.5 & 0.6 & 0.98 & 802.1692 \\
P4 & 0.8 & 1 & 1.2 & 1.02 & 802.1453 \\
P5 & 0.2 & 0.5 & 1.4 & 1.04 & 802.1526 \\
P6 & 0.5 & 3 & 0.5 & 0.9 & 802.1324 \\
P7 & 0.6 & 2 & 0.2 & 0.96 & 802.1315 \\
\hline
\end{tabular}

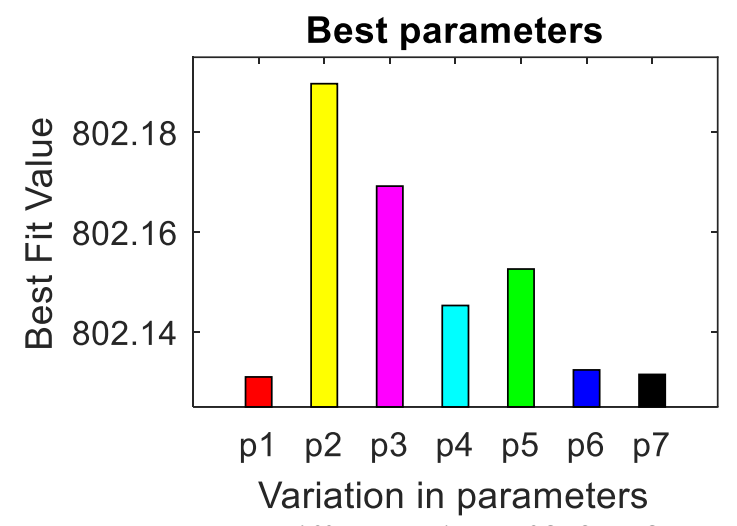

Figure 5. Different values of $\delta, \beta, \gamma, \delta$.

Table 4. Optimal control variable settings for standard test system.

\begin{tabular}{|c|c|c|c|c|c|c|c|c|c|}
\hline Variables & OF_1 & OF_2 & OF_3 & OF_4 & Variables & OF_1 & OF_2 & OF_3 & OF_4 \\
\hline PG1 & 90.3199 & 50.2353 & 194.9750 & 138.8645 & $\mathrm{~T} 1$ & 1.0407 & 1.0414 & 1.1000 & 0.9720 \\
\hline PG2 & 21.3579 & 27.4921 & 63.4769 & 21.5171 & $\mathrm{~T} 2$ & 0.9000 & 0.9000 & 1.0570 & 0.9000 \\
\hline PG3 & 22.9740 & 39.9065 & 30.7186 & 33.1326 & $\mathrm{~T} 3$ & 0.9788 & 0.9786 & 1.1000 & 0.9617 \\
\hline PG4 & 10.0000 & 10.1012 & 34.7066 & 19.3884 & $\mathrm{~T} 4$ & 0.9642 & 0.9645 & 1.0438 & 0.9422 \\
\hline PG5 & 23.5901 & 15.9503 & 14.8880 & 13.0924 & $\mathrm{C} 1$ & 4.9994 & 5.0000 & 4.9998 & 3.7974 \\
\hline PG6 & 39.9717 & 38.8241 & 39.8678 & 20.2796 & $\mathrm{C} 2$ & 5.0000 & 4.9999 & 0.4601 & 3.5771 \\
\hline VG1 & 0.9265 & 0.9083 & 1.0980 & 0.9000 & C3 & 4.3634 & 4.0802 & 5.0000 & 2.4099 \\
\hline VG2 & 1.0999 & 1.0193 & 1.0637 & 1.1000 & $\mathrm{C} 4$ & 5.0000 & 5.0000 & 0.0004 & 4.9863 \\
\hline VG3 & 1.0273 & 0.9166 & 1.0203 & 1.0993 & $\mathrm{C} 5$ & 3.7218 & 3.8049 & 5.0000 & 0.0011 \\
\hline VG4 & 0.9016 & 1.1000 & 0.9006 & 0.9860 & C6 & 5.0000 & 5.0000 & 5.0000 & 1.8336 \\
\hline VG5 & 0.9079 & 0.9404 & 0.9427 & 0.9127 & $\mathrm{C} 7$ & 2.3292 & 2.4416 & 5.0000 & 0.0000 \\
\hline \multirow[t]{6}{*}{ VG6 } & 1.0631 & 1.0792 & 0.9745 & 0.9867 & $\mathrm{C} 8$ & 5.0000 & 5.0000 & 4.9999 & 0.0003 \\
\hline & & & & & C9 & 2.1258 & 2.0945 & 2.6890 & 0.0021 \\
\hline & & & & & TFC (\$/hr) & 802.1309 & 802.1329 & 802.9120 & 802.7650 \\
\hline & & & & & TAPL(MW) & 3.6442 & 3.6439 & 3.8590 & 3.8192 \\
\hline & & & & & TVD (p.u) & 2.0533 & 2.0527 & 0.5078 & 2.0039 \\
\hline & & & & & VSI & 0.1254 & 0.1255 & 0.1462 & 0.1245 \\
\hline
\end{tabular}

Table 5. Best objective function values for standard test system.

\begin{tabular}{lllll}
\hline EAs & OF_1 & OF_2 & OF_3 & OF_4 \\
\hline FFA & $\mathbf{8 0 2 . 1 3 0 9}$ & $\mathbf{3 . 6 4 3 9}$ & $\mathbf{0 . 5 0 7 8}$ & $\mathbf{0 . 1 2 4 5}$ \\
MSA & 802.2238 & 3.6499 & 0.5114 & 0.1246 \\
DA & 802.3183 & 3.6727 & 0.5363 & 0.1250 \\
\hline
\end{tabular}

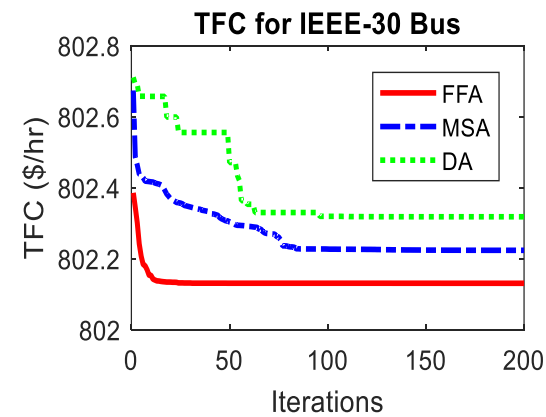

Figure 6. Iterations vs TFC curves

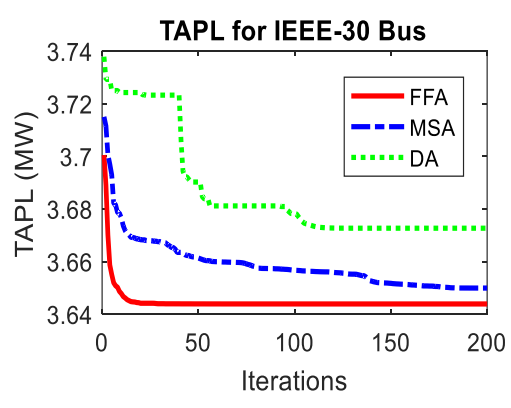

Figure 7. Iterations vs TAPL curves 


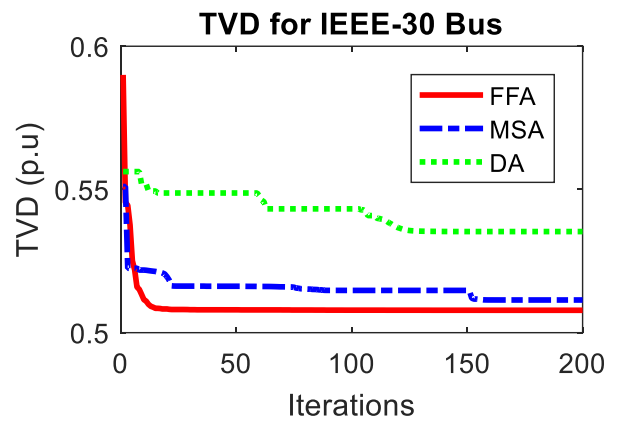

Figure 8. Iterations vs TVD curves

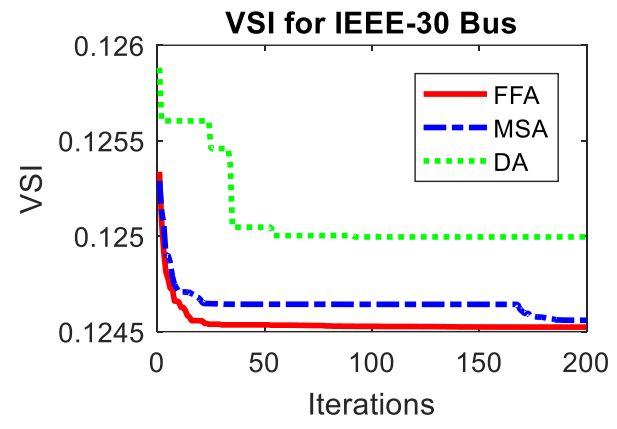

Figure 9. Iterations vs VSI curves

Table 6. Statistical measures for standard test system.

\begin{tabular}{llllll}
\hline OF & EAs & Best & Mean & Worst & Std \\
\hline \multirow{2}{*}{ TFC } & FFA & 802.1309 & 802.1364 & 802.3856 & 0.0283 \\
& MSA & 802.2238 & 802.2702 & 802.6738 & 0.0700 \\
& DA & 802.3183 & 802.3945 & 802.7109 & 0.1217 \\
\hline \multirow{2}{*}{ TAPL } & FFA & 3.6439 & 3.6449 & 3.6439 & 0.0056 \\
& MSA & 3.6499 & 3.6589 & 3.7150 & 0.0099 \\
& DA & 3.6727 & 3.6864 & 3.7379 & 0.0199 \\
\hline \multirow{2}{*}{ TVD } & FFA & 0.5078 & 0.5091 & 0.5900 & 0.0043 \\
& MSA & 0.5114 & 0.5154 & 0.5510 & 0.0045 \\
& DA & 0.5363 & 0.5418 & 0.5562 & 0.0063 \\
VSI & FFA & 0.1245 & 0.1245 & 0.1253 & 0.0000 \\
& MSA & 0.1246 & 0.1246 & 0.1253 & 0.0000 \\
& DA & 0.1250 & 0.1251 & 0.1259 & 0.0002 \\
\hline
\end{tabular}

\section{Conclusion}

The performances of various swarm intelligent algorithms viz., FFA, DA and MSA for solving OPF problem are presented in this paper. Four different objective functions such as minimization of total fuel cost, minimization of total active power loss, minimization of voltage magnitude deviation and improvisation of voltage stability index are considered subject to various hard and soft constraints. The investigations are carried on a standard IEEE 30 bus system. Based on the simulation results, it is acquired that the best values for OPF problem is from FFA. The outstanding parameter values for FFA is considered at $\alpha=0.2, \beta=2, \gamma=1, \delta=0.98$. The best value contributed by FFA is exceptionally near the mean value among 25 trial runs. FFA is much more efficient in finding the global optima with higher success rate and less iteration for four objective functions when compared with MSA and DA. Due to its cognitive nature, FFA outperforms the other algorithms for this test framework. Based on the convergence characteristics and statistical measures such as best, mean and the worst values of various objectives of OPF, FFA has better ability to give optimal solutions than MSA and DA for solving OPF problem.

\section{References}

1. Shareef S M and Srinivasa Rao R (2018). Optimal reactive power dispatch under unbalanced conditions using hybrid swarm intelligence. Computers \& Electrical Engineering, 69, 183-193. doi:10.1016/j.compeleceng.2018.05.011.

2. Fister I, Yang X S and Brest J (2013). A comprehensive review of firefly algorithms. Swarm and Evolutionary Computation, 13, 34-46. doi:10.1016/j.swevo.2013.06.001

3. Yu S, Zhu S, Ma Y and Mao D (2015). A variable step size firefly algorithm for numerical optimization. Applied Mathematics and Computation, 263, 214-220.

4. Pradhan P C, Sahu R K and Panda S. (2016). Firefly algorithm optimized fuzzy PID controller for AGC of multi-area multi-source power systems with UPFC and SMES. Engineering Science and Technology, an International Journal, 19(1), 338-354. doi:10.1016/j.jestch.2015.08.007

5. Gopalakrishnan, R., Mohan, A., Sankar, L. P., \& Vijayan, D. S. (2020). Characterisation On Toughness Property Of Self-Compacting Fibre Reinforced Concrete. In Journal of Environmental Protection and Ecology (Vol. 21, Issue 6, pp. 2153-2163). 
6. Luo Q, Yang X and Zhou Y (2018). Nature-inspired approach: An enhanced moth swarm algorithm for global optimization. Mathematics and Computers in Simulation. doi:10.1016/j.matcom.2018

7. Li L L, Zhao X, Tseng M L and Tan R. R. (2020). Short-term wind power forecasting based on support vector machine with improved dragonfly algorithm. Journal of Cleaner Production, 242, 118447. doi:10.1016/j.jclepro.2019.118447

8. Murugan, S. (2017). Memory based Hybrid Dragonfly Algorithm for numerical optimization problems. Expert Systems with Applications, 83, 63-78. doi:10.1016/j.eswa.2017.04.033

9. Balachennaiah P, Suryakalavathi M and Nagendra P (2018). Firefly algorithm based solution to minimize the real power loss in a power system. Ain Shams Engineering Journal, 9(1), 89-100. doi:10.1016/j.asej.2015.10.005

10. M. Tholkapiyan, A.Mohan, Vijayan.D.S, A survey of recent studies on chlorophyll variation in Indian coastal waters, IOP Conf. Series: Materials Science and Engineering 993 (2020) 012041, 16.

11. C Shilaja and T. Arunprasath. (2019). Optimal power flow using Moth Swarm Algorithm with Gravitational Search Algorithm considering wind power. Future Generation Computer Systems. doi:10.1016/j.future.2018.12.046

12. Suresh kumar K and Ponnusamy V (2019). Power flow management in micro grid through renewable energy sources using a hybrid modified dragonfly algorithm with bat search algorithm. Energy, 181, 1166-1178. doi:10.1016/j.energy.2019.06.029 